\title{
Stage B1
}

National Cancer Institute

\section{Source}

National Cancer Institute. Stage B1. NCI Thesaurus. Code C28058.

Cancer that has reached but has not invaded the muscularis propria of the colon, or cancer confined to one lobe of the prostate gland as a single lesion. 